\section{PROJEKTOVANjE GLEDALIŠTA U SPORTSKOM OBJEKTU}

\section{DESIGN OF THE AUDITORIUM IN SPORT FACILITIES}

\begin{abstract}
Abstrakt:
Gledališta je važan element za pravilnu percepciju događaja na sportskom terenu. Veliki broj elemenata utiču na kvalitet gledališta: sagledljivost
\end{abstract} sportskog terena, maksimalne/minimalne distance sagledavanja, brzina i veličina lopte, itd. Odnos između gledališta i sportskog terna mora biti pažljivo uspostavljen. Potrebno je sprečiti ulazak gledalaca na teren, i povređivanje gledalaca. U praksi se primenjuju tri oblika razdvajanja gledališta od sportskog terena: Perimetarska ograda, Rovovi, Promena nivoa poda. Prilikom projektovanja gledališta potrebno je definisati: sagledljivost sportskog terena, kapacitet, distance za sagledavanje, tip sedišta, stepen komfora sedenja, standarde za kategoriju takmičenja, strukturu sedišta, itd. Cilj rada je analiza pojedinih elemenata gledališta. Rezultat rada treba da pomogne povećanju kvaliteta usluge, i zadovoljstva gledalaca sportskog objekta.

Ključne reči: gledalište, perimetarska ograda, rovovi, promena nivoa poda, sagledljivost sportskog događaja, sedišta u gledalištu.

\section{Duško Kuzović ${ }^{1}$}

${ }^{1}$ Dhofar University, College of Engineering, Department of Architecture Engineering

Salalah, Sultanate of Oman doi:10.5550/sgia.181401.se.k UDK: 796.02

Primljeno: 12.02.2018. Odobreno: 10.06.2018.

Korespodencija: Assist. Prof.Dr. Duško Kuzović, dipl. eng.arch. Faculty of Civil and Enviromental Enginnering Dzofar University, Salalah, Sultanate of Aman dusko.kuzovic@gmail.com dkuzovic@du.edu.om

Sportlogia 2018, 14 (1), 37-46. E-ISSN 1986-6119

\footnotetext{
Kuzović, D. (2018). Projektovanje gledališta u sportskom objektu.Sportlogia, 14 (1), 37-46. doi:10.5550/sgia.181401.se.k
} 


\section{UVOD}

Gledalište, pored sportskog terena, je najvažniji segment sportskog objekta. Od udobnosti gledališta zavisi stepen zadovoljstva posmatrača, i interakcija sa dešavanjima na sportskom borilištu. Stoga je pravilno projektovanje gledališta od primarne važnosti. Takođe, kod postojećih sportskih objekata provera postojećih rešenja može doneti saznanja koja će biti korisna na unapređenju kvaliteta sportskog objekta. Cilj rada je definisanje osnovnih elemenata gledališta u sportskom objektu, sagledavanje standarda za organizaciju, oblikovanje, veza, i strukture prostora. Takođe, cilj rada je da se specificiraju osobine koje mora da poseduje prostor gledališta. Rezultat rada treba da pomogne u vrednovanju novih i postojećih prostora $u$ sportskom objektu, uočavanje nedostataka i neophodnih izmena.

Literaturu, korištena za ovaj rad, čine publikacije FIFA (FIFA, 2004; FIFA, 2011a; FIFA, 2011b), UEFA (UEFA, 2011a; UEFA, 2011b; UEFA, 2011c), OECD (OECD, 2011), specijalizovanih službi državnih administracija (Department for Culture, Media and Sport, 2008), kvalitetna publikacija o projetovanju sportskog objekta ,STADIA: A Design and Development Guide" Geraint, Sheard \& Vickery (Geraint, Sheard i Vickery, 2007). Važne publikacija koje obrađuje navedenu temu je knjiga Rudolpha Ortner ,Sportbauten, Anlage-BauAusstatug“ (Ortner, 1956), potom knjiga ,Arhitekturnoe proektirovanie obmestvennblh zdaniŭ $i$ sooruženiü“" iz Rusije (Rožin, Urbah, Adamovič, Barhin, Varežkin, Vinogradova, Gaŭnutdinov, Gnedovskiй, Golubev, Gusev V.V., Gusev N.M., Erofeeva N.M., Erofeeva N.N., Zmeul, Ionov, Krasilınikov, Matveenko, Movčan, Obolenskiй, Ovsяnnikov, Opočinskaя, Platonov, Popov, Rannev, Roщin, Satunc, Sergeev i Cыtovič, 1985), zatim knjiga „Sporski objekti“ Slobodana Ilića (Ilić, 1998) i Miroslava Mitrovića „Sportski objekti, Sadržaj i obeležja igre i sporta u stambenoj sredini $i$ naselju“ (Mitrović, 1983). Takođe, korisne informacije mogu da donesu i publikacije koje tretiraju bezbednost u sportskom objektu „The facility manager's guide to environmental health and safety" Gallant (Gallant, 2008), i McGregor \& Shiem-Shin Then „Facilities Management and the Business of Space” (McGregor i Shiem-Shin, 2003).

\section{DISKUSIJA}

Kontrola kretanja posetilaca je jedan od glavnih zadataka osoblja koje upravlja sportskim objektom. Tom prilikom, pored jasno definisanih putanja kretanja, potrebno je predvideti ponašanje pojedinca ili grupe (u zavisnosti od događaja na terenu i oko terena). Pri tome treba imati u vidu da se ponašanje grupe može značajno razlikovati od ponašanja pojedinca koji formiraju grupu. Razlozi koji okupljaju pojedince da se udružuju u grupu kako bi posećivali sportski događaj su raznorodni i zavise od mnogo okolnosti. Veoma malo energije je potrebno da zajednica mirnih pojedinaca promeni ponašanje, formira grupu i postane generator problema u sportskom objektu. Stoga je proučavanje, stalni nadzor i rad na predviđanju ponašanja grupe od ključne važnosti za uspešnu realizaciju sportskog događaja koji uključuje i publiku. Ukoliko je ponašanje gledalaca suprotno kućnom redu u objektu potrebno je da osoblje brzo i precizno reaguje što podrazumeva jasne pravce delovanja, za koje je potrebno obezbediti prostor prilikom projektovanja. Potrebno je opominjati publiku da se ponaša u skladu sa pravilima kućnog reda, za šta su potrebna sredstva komunikacije. Iskustvo govori da ukoliko je objekat nov (ili nedavno renoviran) publika se ponaša više u skladu sa propisima. Ukoliko se na objektu previše jasno i uočljivo koriste rešenja kojim se sprečava vandalizam za očekivati je da se u publici javlja više vandalizma. Glavna intencija upravljanja ponašanjem publike u gledalištu je destimulacija izlaska na sportski teren; da se ponaša prema propisanom kućnom redu; da se spreči vandalizam na gledalištu. Ne treba izgubiti iz vida, publika je izvor značajnog dela dohotka. Prema istraživanjima u SAD 92\% publike vrednuje način ponašanja osoblja prema njoj (Geraint, Sheard i Vickery, 2007). Publika je korisnik, a zadovoljnost korisnika, je važna kao i u drugim uslužnim delatnostima. 


\section{Gledalište - Sportski teren}

Osnovna dva razloga, zbog kojih je potrebno razdvajanje gledališta od sportskog terena, su zaštita igrača i osoblja od nasilnih gledalaca i zaštita terena od oštećenja obućom i težinom. U kritičnim sutiacijama, publika smatra slobodan sportski teren kao sigurno mesto kome teže svi koji se nalaze u publici. Masivna ograda je smetnja sagledavanju sportskog događaja. Potom, potencijali je izvor povreda koje nastupaju kod posetilaca pritisnutih uz ogradu (u slučaju panike). Stoga, lokacija i tip ograde mora biti pažljivo odabran, uz poštovanje sledećih faktora: ograda je potrebna u slučaju fudbalskog meča (manje u ostalim sportskim disciplinama na istom terenu), lokalni običaji na nekim mestima u Evropi zahtevaju da publika nosi na ramenima kapitena (isti praksa, na drugim mestima, je zabranjena). U praksi se primenjuju tri osnove tehnike razdvajanja gledalaca od sportskog terena: perimetarska ograda, rovovi i promena nivoa. (Geraint, Sheard i Vickery, 2007; UEFA, 2011; FIFA, 2011).

\section{a. Perimetarska ograda}

Preporuke FIFA i UEFA 2006. godine, govore da se mečevi najvišeg nivoa ne mogu igrati na terenima koji su ograđeni visokom ogradom. Ukoliko se planiraju, visoke ograde moraju imati izlaze za slučaj opasnosti. Preporuke „Guide to Safety at Sports Grounds” (Department for Culture, Media and Sport, 2008) propisuju da, na novim terenima se ne praktikuje perimetarska ograda. Na objektima gde postoji ograda: ne sme biti viša od 2,2 metra; mora biti stabilna; mora biti u stanju da se suprotstavi pritisku grupe navijača; da sadrži ispust širine 1,1 metar. Ograda mora biti tako oblikovana da na nju ne mogu navijači da se penju. Ograda mora biti takva da ne sprečava / ometa pogled na sportski teren. Na njoj mora biti izlaz za evakuaciju u pravcu sportskog terena (u formi kapije ili panela). Izlazi moraju da se otvaraju ili sklapaju. Broj i raspored otvora u ogradi se određuje prema broju gledalaca. Izlazi moraju biti jasno i vidljivo označeni. Na višenamenskim objektima ograda mora montažno-demontažna. Bez obzira na tip ograde, mora postojati stalni nadzor osoblja sportskog objekta. (FIFA, 2004; FIFA, 2011a; FIFA, 2011b; UEFA, 2011; UEFA 2011b).

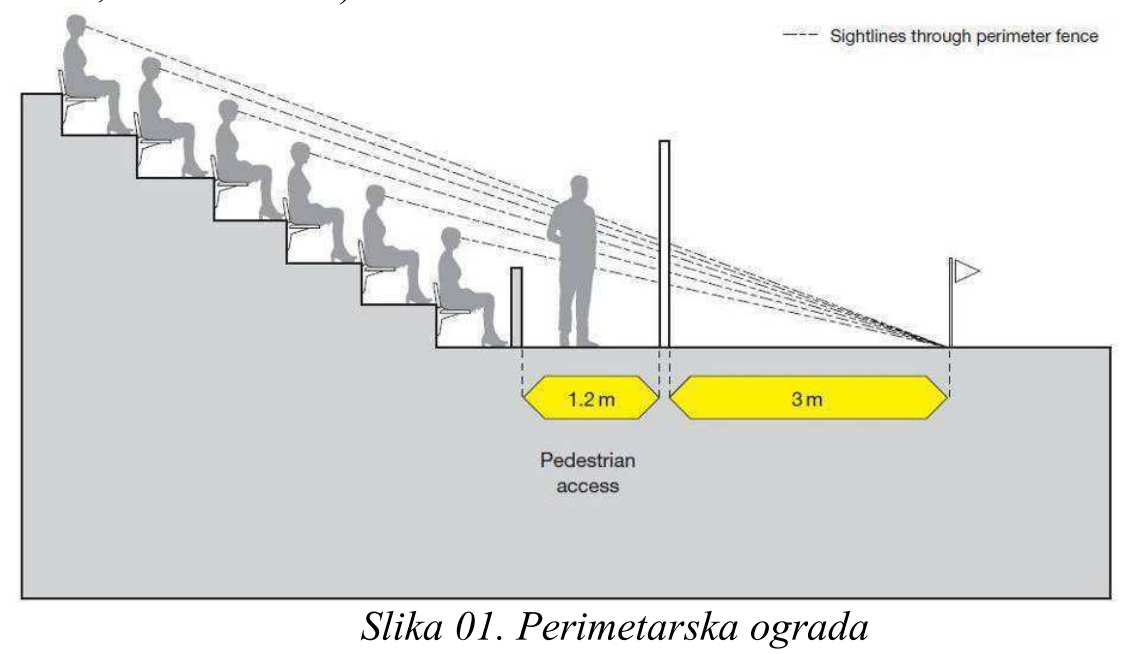

\section{Rovovi}

Rovovi su građevinske konstrukcije kojima se razdvaja gledalište od sportskog terena. Rovovi služe ujedno kao trasa za kretanje oko sportskog terena (za osoblje objekta i obezbeđenje, medicinsko osoblje, medije). Širina i i visina rovova mora uskladiti sa potrebama navedenih grupa korisnika. Prema preporukama FIFA minimalna širina rova je 2,5 metara a dubina 3,0 metra. Nedostatak rovova je što povećava distancu između gledališta i sportskog terena. Stoga su rovovi pogodniji za velike stadione (na koje malo utiče širina rova od 2,5-3,0m). Rovovi moraju da imaju, na određenom razmaku, izlaze za evakuaciju u nivou poda. Rovovi ne smeju imati vodu po podu. U slučaju potrebe, radi pristupa vozila na sportski teren, moraju imati prelaz u vidu mosta (koji može da izdrži težinu i udar očekivanog tipa vozila). Potrebno je

Kuzović, D. (2018). Projektovanje gledališta u sportskom objektu.Sportlogia, 14 (1), 37-46. doi:10.5550/sgia.181401.se.k 
obezbediti pristup gledalaca rovu stepenicama i silazima odgovarajuće širine. Ukoliko se rovovi koriste kao mesto za deponovanje otpaada prilikom čišćenja gledališta, moraju imati otvore u ogradi. Pristup rovovima (igrača, izvođača i policije) mora biti kroz tunele ili pokrivene prolaze. Kiosci za prodaju mogu biti locirani i u rovu ukoliko ne sužavaju minimalnu širinu prolaza (Geraint, Sheard i Vickery, 2007).

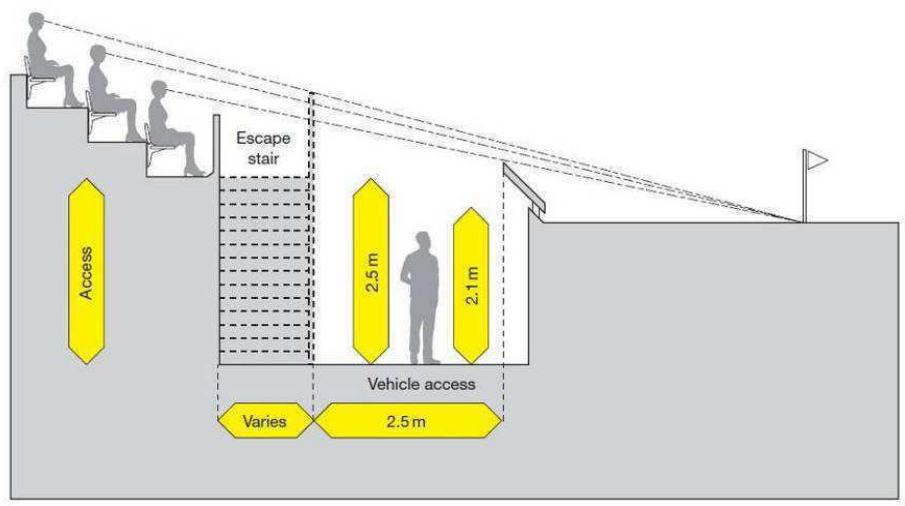

Slika 02. Rovovi

\section{Promena nivoa}

Promena nivoa poda je povišenje / sniženje poda između gledališta i sportskog terena (prema propisima i standardima). Promene visine poda su manje od dubine rova a manje od visine ograde. Realizuju se podizanjem prvog reda gledališta iznad terena, tako da prelazak na teren je težak ili nemoguć. Prednost ovakvog rešenja je u tome što akteri događaja na sportskom terenu, se mogu locirati pored ogradnog zida ne ometajući gledaoce. Međutim, promena nivoa poda je smetnja samo za malo motivisane gledaoce. Ako se očekuje pristojno ponašanje gledalaca promena nivoa poda je korisna. Uobičajena visina prvog reda (u odnosu na teren) je 1,5 do 2,0 metara. Na pomenutu visinu se dodaje još 1,0 metar visoka ograda. Podizanjem prvog reda u gledalištu postiže se bolja vidljivost (FIFA, 2004; FIFA, 2011a; FIFA, 2011b; UEFA, 2011; UEFA, 2011b).

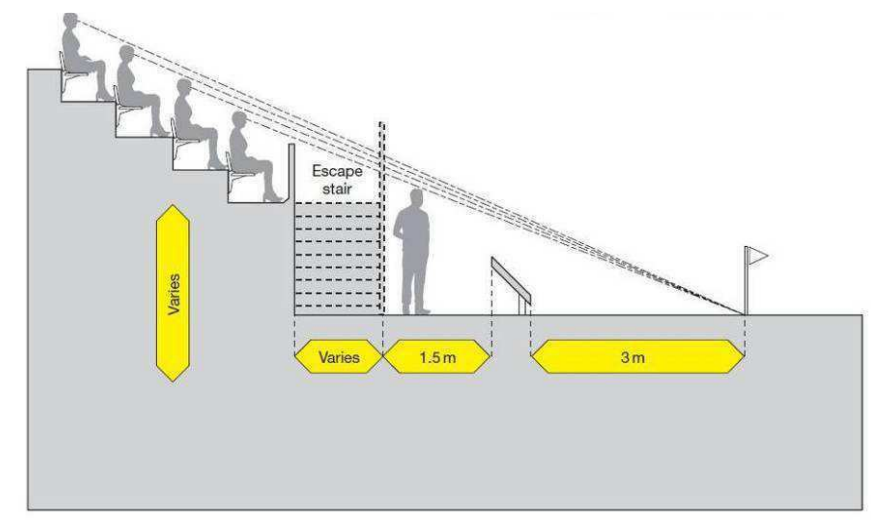

Slika 03. Promena nivoa poda između gledaišta i sportskog terena.

\section{Gledalište}

Osnovna obaveza osoblja koji upravlja sportskim objektom je da svim gledaocima omogući kvalitetan i jasan pregled dešavanja na sportskom terenu. Faktori koji utiču na kvalitet sagledavanja su: uočljivost centralnog predmeta sportskog takmičenja sa mesta u gledalištu, orjentacija sportskog terena, veličina terena, veličina lopte, brzina kretanja lopte. Na osnovu navedenih činjenica se određuje maksimalna udaljenost gledaoca (da se pri tome ne ugrozi vidljivost i sagledljivost igre). Ovaj podatak određuje maksimalni kapacitet sportskog objekta. Povećanje kapaciteta sportskog objekta treba vršiti kada postoje puni dokazi da će se zadržati kvalitet sagledavanja gledalaca. Sportski objekat može da primi duplo više gledalaca ukoliko su tribine projektovane za stajanje (ne za sedenje). Za međunarodna takmičenja pravila zahtevaju

Kuzović, D. (2018). Projektovanje gledališta u sportskom objektu.Sportlogia, 14 (1), 37-46. doi:10.5550/sgia.181401.se.k 
isključivo sedeća mesta. Na donošenje odluke o povećanju broja mesta u gledalištu uticaj mogu imati: veličina gravitacione zone objekta, mogućnosti sponzora, istorija kluba, mogućnosti lokacije, kvalitet vizure novih mesta, pokrivenost krovom, estetski kvalitet objekta, troškovi izgradnje / rekonstrukcije, troškovi osoblja / obezbeđenja, mogućnosti infrastrukture, struktura sedišta (VIP, službenike, direktore, hendikepirane) itd.
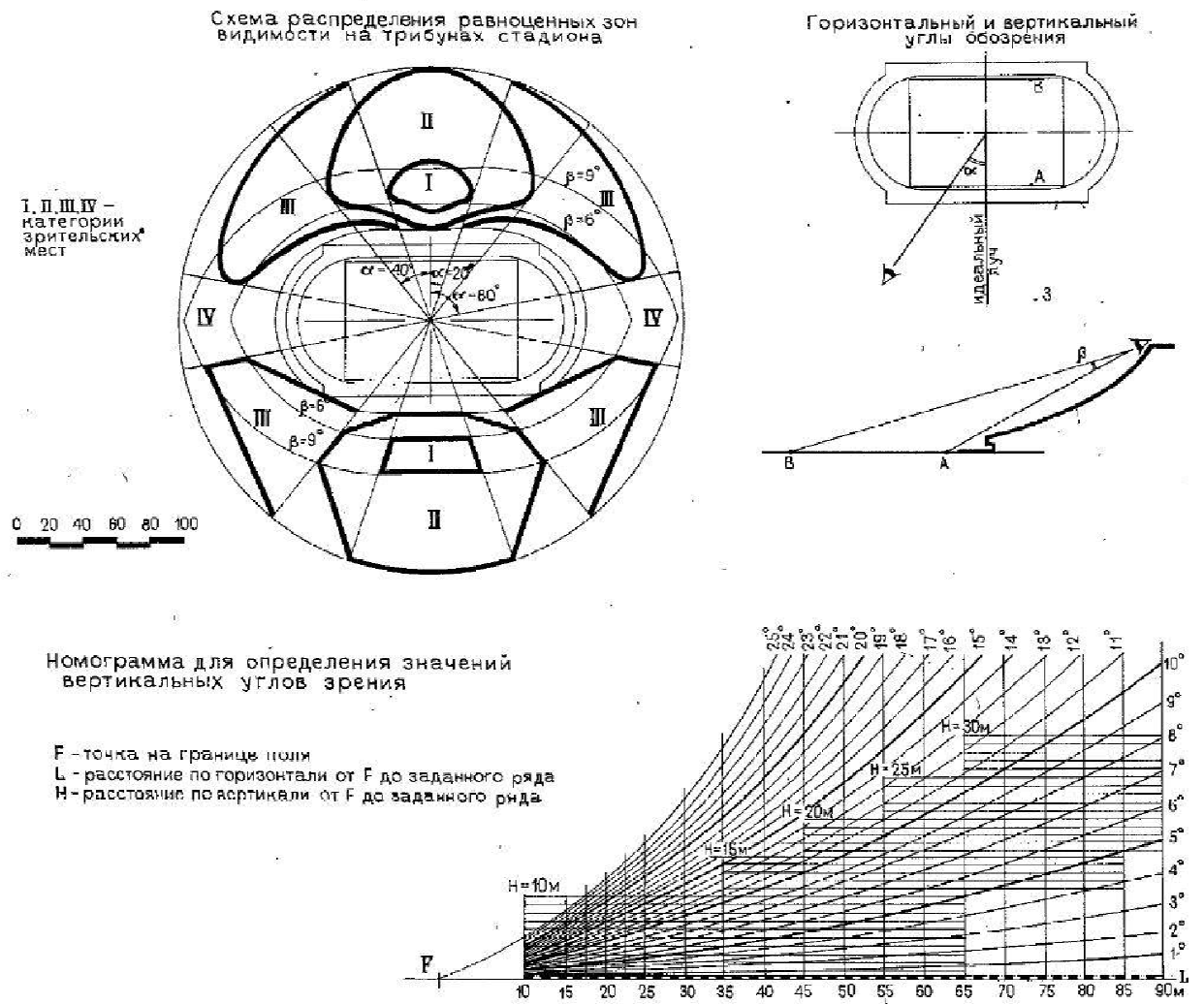

Slika 04: Kategorije sagledljivosti pojedinih delova gledališta (prema Polikarpovu).

Kapacitet gledališta sportskog objekta zavisi od gravitacione zone. Što je brojnija gravitaciona zona objekta, razlozi za povećanje broja mesta za gledaoce su veći. Odluka o početnom broju gledalaca treba da bude doneta na osnovu umerenih procena. Takođe, planirati mogućnost da se broj gledalaca povećava (kroz dogradnju / proširenje). Proširenje može biti jednokratno ili u više faza.

Distance za sagledavanje su maksimalne udaljenosti sa kojih se nesmetano uočava centralni predmet sportskog događaja. Zasnivaju su na biološkim karakteristikama ljudskog oka. Ljudsko oko veoma teško uočava predmete koji su van ugla od 0,4 stepena. Ukoliko se premet koji se posmatra kreće brzo, sagledavanje se otežava. Na taj način se dolazi do proračuna da maksimalna udaljenost koja garantuje vidljivost predmeta koji je $250 \mathrm{~mm}$ u prečniku (fudbalska lopta) iznosi 150 metara, apsolutni maksimum je 190 metara. Za tenis (prečnik lopte $75 \mathrm{~mm}$ ) maksimalna distanca iznosi 30 metara (BS EN 13200- 2003 Spectator facilities - Part 1: Layout criteria for spectator viewing area - specification). Uobičajeno rešenje (za fudbal) se zasniva kroz formiranje kružnice prečnika 90 metara koja ima središte u centru sportskog terena (linije pretpostavljene optimalne vidljivosti za gledaoca). Tačka fokusa je tačka u nivou poda sportskog terena u odnosu na koju se određuje sagledljivost sa gledališta. Kod višefunkcionalnih objekata (gde se koriste lopte različitog prečnika) maksimalna vidljivost se menja, što utiče na geometriju gledališta. Takođe, pomenuta dimenzija 90 metara se zasniva na horizontalnoj projekciji. Međutim, gledaoci sede na tribinama koje se postepeno uzdižu od nivoa terena (do 20 metara), čime se udaljenost od fokusne tačke postepeno povećava. Pomenuto udaljenje treba uzeti u obzir prilikom procene sagledljivosti sa određene tačke (Grupa autora,1985). Posebnu pažnju treba

Kuzović, D. (2018). Projektovanje gledališta u sportskom objektu.Sportlogia, 14 (1), 37-46. doi:10.5550/sgia.181401.se.k 
posvetiti rešenju uglova gledališta. Isključenje ove zone iz gledališta donosi jevtiniju izgradnju, bolje provetravanje sportskog terena, i isključuje za gledaoce najmanje vrednovanu lokaciju.

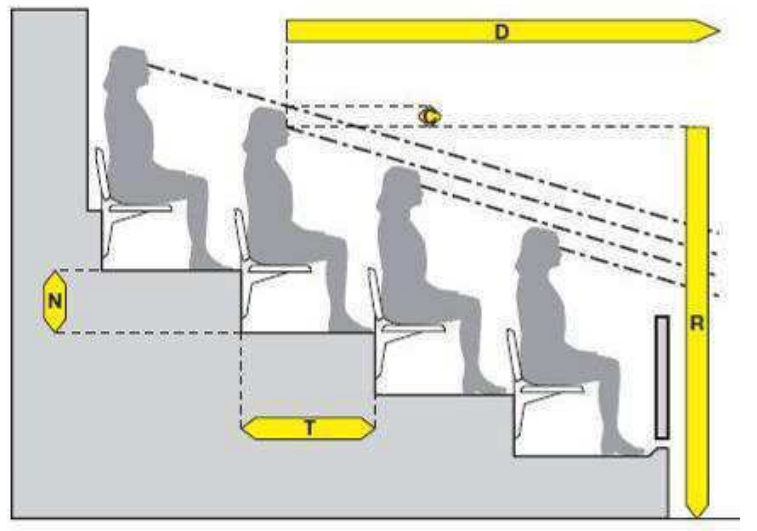

Slika 05. Sagledljivost sportskog terena

Sedišta zahtevaju pažljivo oblikovanje. Osnovni preduslovi su: da je gledalište dovoljnog kapaciteta, gledaoci su blizu prostoru aktivnosti najviše moguće, najveći broj gledalaca bira mesta koja preferiraju (u odnosu na sportski teren). Na osnovu navedenog se formira ,linija vidljivosti“'. Linija se zasniva na mogućnosti da gledalac komotno vidi najbljižu tačku od interesa na sportskom terenu - ,tačku fokusa“. Matematički ovaj odnos se izražava na sledeći način:

$\mathrm{N}=[(\mathrm{R}+\mathrm{C}) *(\mathrm{D}+\mathrm{T}) / \mathrm{D}]-\mathrm{R}$

gde je:

$N$ - korak uzdizanja

$R$ - visina između oka na tački fokusa na sportskom terenu

D - distanca od oka do tačke fokusa na sportskom terenu

$C$ - ,C" vrednost (150 mm za gledaoce sa šeširom, $120 \mathrm{~mm}$ za stajaće mesto sa dobrom vidljivosti, $90 \mathrm{~mm}$ gledalac sa glavom nagnutom unazad, $60 \mathrm{~mm}$ između glava gledalac u redu).

$T$ - dubina reda sa sedištima

Za gledaoce sa hendikepom odnos u formuli se menja (u skladu sa preporukama). U praksi se projektuju posebne platforme za ovu vrstu gledalaca (UEFA, 2011c). Preporuke za projektovanje gledališta: (BS EN 13200- 2003)

1. Definisati tačku fokusa na sportskom terenu (tačka koja ima najmajnje uslove za sagledavanje). 2. Opredeliti vrednost koeficijenta „C“ (60-150 mm). Osnovni cilj je da gledaoci imaju maksimalnu sagledljivost. 3. Opredeliti udaljenost između prvog reda sedišta i tačke fokusa. 4. Opredeliti visinu prvog reda sedišta u odnosu na sportski teren (ne manja od $80 \mathrm{~cm}$ ).

Nagib gledališta se može kretati od $34^{\circ}$ (maksimalno) stepena pa naniže. Posledica izbora ugla gledališta je visina gledališta. (Department for Culture, Media and Sport, 2008).

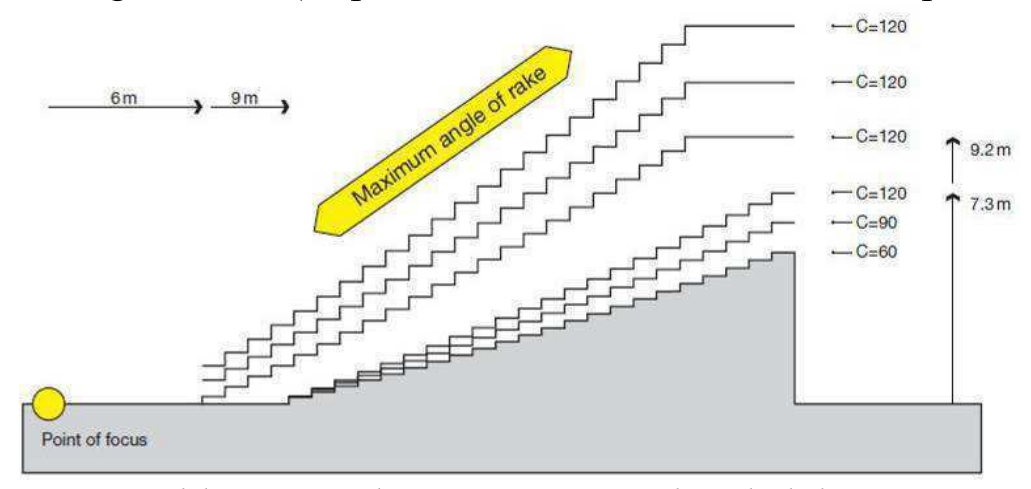

Slika 06:Analiza promene nagiba gledališta

Zadovoljstvo gledalaca gledalištem se može analizirati kroz četiri elementa: komfor, bezbednost, robustnost i ekonomija (Geraint, Sheard i Vickery, 2007). Komfor zavisi od dužine sedenja gladaoca u sedištu (zavisi od vrste sporta). Komfor je jedna od najskupljih kategorija ali

Kuzović, D. (2018). Projektovanje gledališta u sportskom objektu.Sportlogia, 14 (1), 37-46. doi:10.5550/sgia.181401.se.k 
i glavna sila koja privlači gledaoce. Bezbednost treba posmatrati sa stanovišta kontrole gledalaca, rešenja kojima se olakšava kretanje službi (policije, Hitne pomoći, obezbeđenja, servisnih službi, osoblja objekta), vrste materijala sedišta (bezbednost od požara, vandalizma). Materijal za sedišta mora biti otporan na vremenske uslove, robustan i udoban. Najpopularniji materijal je polipropilen, polietilen, najlon, PVC ili armirana providna plastika. Zbog opasnosti od vandalizma sve se više koriste držači sedišta načinjeni od plastičnih materijala. Sedišta moraju biti jednostavna za čišćenje a učvršćivanje mora biti robustno. Očekivani vek upotrebe ovakvih sedišta je do 20 godina. Savremena sedišta (u pojedinim zonama gledališta sportskog objekta) treba da imaju držače za čašu / program / dvogled. Pojedina sedišta imaju mobilne komunikacione uređaje kojima se naručuje posluženje. Sedišta za gledaoce sa hendikepom zavise od lokacije u gledalištu. Broj sedišta zavisi od ukupnog broja mesta u sportskom objektu. Lokacija mesta za hendikepirana lica mora biti pristupačna (od ulaza do mesta) (UEFA, 2011c).
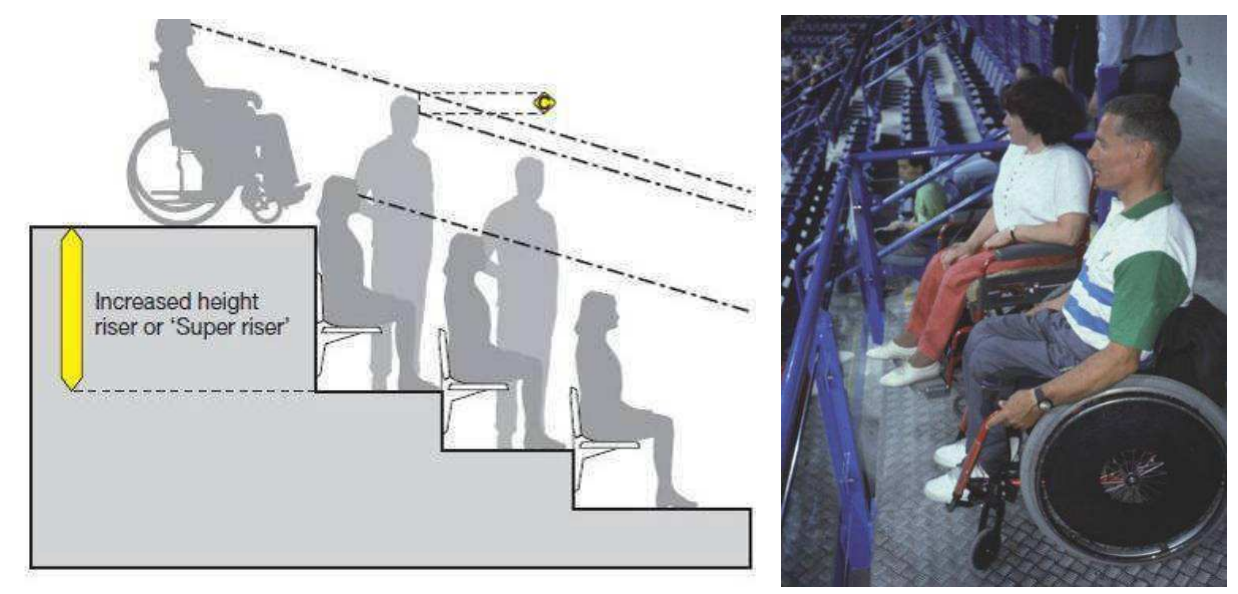

Slika 07. Gledalište sa platformom za hendikepirana lica.

Ekonomija (konstrukcije i materijal sedišta) zavisi od budžeta investitora. Može se kretati od jevtinih materijala poput drveta do savremenih rešenja (nesklapajuća/ sklapajuća sedišta). Sedišta mogu biti ugrađena kao grupe ili kao pojedinačna. Dubina redova sedišta se kreću od 700 - $800 \mathrm{~mm}$. Ukoliko sedište ima naslon širina je $500 \mathrm{~mm}$, bez naslona za ruke je $460 \mathrm{~mm}$. Preporuke definišu širinu sedišta od $500 \mathrm{~mm}$ kao minimalno za kvalitetno sedenje (BS EN 13200-2003). Struktura sedišta zavisi od vrste sporta i ekonomske strukture gledalaca. Sportski objekti sa širokim dijapazonom usluga su pogodniji za višenamenske sadržaje. Struktura sedišta u gledalištu je data u Tabeli 1 (Geraint, Sheard i Vickery, 2007). 


Privatna sedišta
Izvršna sedišta
Klupska sedišta
Članovi - sedenje i
obedovanje
Članovi - sedenje
Javno sedenje
Generalno - sedenje
Teniski boksovi
Terase za stajanje

\section{ZAKLjUČAK}

Gledališta je važan element za pravilnu percepciju sportskog događaja. Zadovoljstvo gledalištem je osnovno merilo prilikom vrednovanja sportskog objekta. Projektovanje novog ili rekonstrukcija postojećeg gledališta se mora zasnivati na sledećim analizama: sagledljivost sportskog terena, veličina i brzina kretanja lopte, maksimalne / minimalne distance za sagledavanje, itd. Odnos između gledaišta i sportskgo terna mora biti pažljivo uspostavljen. Potrebno je sprečiti ulazak gledalaca na teren i, povređivanje gledalaca usled izbora tipa ograde. U praksi se primenjuju sledeći oblici razdvajanja gledališta od sportskog terena: Perimetarska ograda, Rovovi, Promena nivoa poda. Prilikom projekovanja gledališta potrebno je definisati sledeće elemente: sagledljivost sportskog terena, kapacitet terena, distance za sagledavanje, tip sedišta za posetioce, stepen komfora sedenja gledalaca, standarde sedišta za adekvatnu kategoriju takmičenja, strukturu sedišta, itd. Pravilnim razumevanjem uloge pojedinih elemenata gledališta postiže se bolji kvalitet projekta i povećava zadovoljstvo gledalaca.

\section{POREKLO ILUSTRACIJA}

Slika 01, 02, 03, 05, 06, 07: Geraint J., Sheard R., \& Vickery, B. (2007). STADIA: A Design and Development Guide, Elsevier, Limited.

Slika 04: Rožin I.E., Urbah A.I., Adamovič V.V., Barhin B.G., Varežkin V.A., Vinogradova M.V., Gaйnutdinov I.G., Gnedovskiй Ю.P., Golubev G.E., Gusev V.V., Gusev N.M., Erofeeva N.M., Erofeeva N.N., Zmeul S.G., Ionov I.I., Krasilınikov V.D., Matveenko A.I., Movčan G.Я., Obolenskiй N.V., Ovsяnnikov A.V., Opočinskaя A.I., Platonov Ю.P., Popov A.N., Rannev V.R., Roщin A.V., Satunc S.H., Sergeev K.I., \& Cutovič G.N. (1985) Arhitekturnoe proektirovanie obmestvennblh zdaniŭ i sooruženiŭ, Moskva, RUS: Stroŭizdat.

Kuzović, D. (2018). Projektovanje gledališta u sportskom objektu.Sportlogia, 14 (1), 37-46. doi:10.5550/sgia.181401.se.k 


\title{
LITERATURA
}

BS EN 13200-2003, (2003). Spectator facilities - Part 1: Layout criteria for spectator viewing area specification. BSI.

Department for Culture, Media and Sport (2008). Guide to Safety at Sports Grounds. London, GBR: Department for Culture, Media and Sport.

FIFA (2004): Safety Regulations, Zurich, SUI: FIFA.

FIFA (2011). FIFA Stadium Safety and Security Regulations. Zurich, SUI: FIFA.

FIFA (2011): Football Stadiums, Technical Recommendations and Requirements, Zurich, SUI: FIFA.

Gallant, B. (2008). The facility manager's guide to environmental health and safety. Lanham, USA: Government Institutes.

Geraint, J., Sheard, R., \& Vickery B. (2007). STADIA: A Design and Development Guide, Amsterdam, NED: Elsevier.

Ilić, S. (1998). Sportski objekti. Beograd, RS: Izdanje autora.

McGregor, W., \& Shiem-Shin, T. D. (2003): Facilities Management and the Business of Space, Oxford, GBR: Butterworth-Heinemann.

Mitrović, M. (1983). Sportski objekti, Sadržaj i obeležja igre i sporta u stambenoj sredini $i$ naselju. Beograd, RS: Arhitektonski fakultet.

OECD (2011). Preventing and Reducing Armed Violence in Urban Areas: Programming Note, Conflict and Fragility. Paris, FRA: OECD Publishing. https://doi.org/10.1787/9789264107199-en

Ortner, R. (1956). Sportbauten, Anlage-Bau-Ausstatug, München, GER: Calwey.

Рожин И.Е., Урбах А.И. (ред), Адамович В.В., Бархин Б.Г., Варежкин В.А., Виноградова М.В., Гайнутдинов И.Г., Гнедовский Ю.П., Голубев Г.Е., Гусев В.В., Гусев Н.М., Ерофеева Н.М., Ерофеева Н.Н., Змеул С.Г., Ионов И.И., Красильников В.Д., Матвеенко А.И., Мовчан Г.Я., Оболенский Н.В., Овсянников А.В., Опочинская А.И., Платонов Ю.П., Попов А.Н., Раннев В.Р., Рощин А.В., Сатунц С.Х., Сергеев К.И., \& Цытович Г.Н. (1985). Архитектурное проектирование общественных зданий и сооружений, Москва, RUS: Стройиздат.

UEFA (2011a). UEFA Guide To Quality Stadiums. Genève, SUI: UEFA.

UEFA (2011b). UEFA Stadium Infrastructure Regulations. Genève, SUI: UEFA.

UEFA (2011c). Access For All. Genève, SUI: UEFA.

\begin{abstract}
Auditorium is an important element for the correct perception of events in the sports field. Many elements influence the quality of the auditorium: the perception of the sports field, the maximum I minimum distance of the viewing, the speed and size of the ball, etc. The relationship between the theater and the sport field must be carefully established. It is necessary to prevent spectators entering in the field, and spectators injures. In practice, three forms of auditorium - sports field separation are applied: perimeter fence, trenches, change of floor level. Before the design process starts, it is necessary to define: the visibility of the sport field, the capacity of the auditorium, the minimum/maximum viewing distance, the type of seats, the level of seating comfort, the competition category seating standards, the structure of the seats, etc. The aim of the paper is to analyze the individual elements of the auditorium. The result of the work should increase the quality of design service, and satisfaction of the spectators of the sports facility.
\end{abstract}

Keywords: auditorium, perimeter fence, trenches, floor level change, visibility of a sports event, auditorium seats. 
Primljeno: 12.02.2018.

Odobreno: 10.06.2018.

Korespodencija: Assist. Prof.Dr. Duško Kuzović, dipl. eng.arch. Faculty of Civil and Enviromental Enginnering Dzofar University, Salalah, Sultanate of Aman dusko.kuzovic@gmail.com dkuzovic@du.edu.om 